\title{
Standard 12-lead electrocardiogram tele-transmission: Support in diagnosing cardiovascular diseases in operations undertaken by Warsaw-area basic medical rescue teams between 2009 and 2013
}

Jerzy Rekosz ${ }^{1}$, Maria Kasznicka ${ }^{1}$, Dorota Kwiatkowska ${ }^{1}$, Renata Mączyńska-Mazuruk ${ }^{1}$, Katarzyna Kołak ${ }^{1}$, Beata Mierzejewska ${ }^{1}$, Dorota Drogosiewicz ${ }^{1}$, Dariusz Timler ${ }^{2}$, Robert Gałązkowski ${ }^{3}$

${ }^{1}$ Cardiac Department of the Voivodship Emergency Service and Medical Transport Station (WSPRiTS) "Meditrans", Warsaw, Poland

${ }^{2} 3^{\text {rd }}$ Department of Emergency Medicine and Disaster Medicine, Medical University of Lodz, Lodz, Poland ${ }^{3}$ Department of Emergency Medical Services, Medical University of Warsaw, Warsaw, Poland

\begin{abstract}
Background: Basic medical rescue teams (BMRTs) administer aid in the pre-hospital phase to people in a life-threatening condition. A tele-transmission and teleconsultation system (TTaTC) supports the team without a physician. The aim of the presented study was to evaluate the application and spectrum of use of a 12-lead ECG TTaTC in BMRT operations.

Methods: Medical records of BMRTs in Warsaw from September 2009 to August 2013 regarding TTaTC were checked. Successful TTaTC, electrocardiography (ECG) results, sex, age, consultant advice, and decisions of BMRT leaders were analyzed.

Results: BMRTs performed 28,557 12-lead ECG transmissions within the analyzed period. The teams recorded 26,208 (91.8\%) successful tele-transmissions, while 2,349 tests (8.2\%) failed to reach the TC. The average TTaTC time was 6 min $12 \mathrm{~s}$. The most common reason for using the ECG TTaTC was chest pain. ST-segment elevation myocardial infarction (STEMI) was diagnosed in $2.1 \%$ of the cases, and non-ST segment elevation myocardial infarction - NSTEMI - in 3.8\%. Cardiac arrhythmia was recorded in $20.5 \%$ of the events. TTaTC proved to be useful when making decisions on transporting patients to appropriate hospitals. One hundred percent of STEMI cases - all confirmed by TC - were transported directly to cardiac centers.
\end{abstract}

Conclusions: 1. TTaTC constitutes an increasing support in BMRT everyday operations and is widely used. 2. Standard ECG TTaTC with a physician improved BMRT diagnostic capacities and exerted a beneficial impact on cardiovascular patient segregation and target hospital selection. 3. It seems possible to expand the scope of operations performed by BMRT members based on TTaTC. (Cardiol J 2015; 22, 6: 675-682)

Key words: medical rescue teams, electrocardiogram tele-transmission system, cardiovascular diseases

Address for correspondence: Robert Gałązkowski, PhD, Department of Emergency Medical Services, Medical University of Warsaw, ul. Żwirki i Wigury 81a, 02-091 Warszawa, Poland, e-mail: r.galazkowski@lpr.com.pl; Jerzy Rekosz, MD, PhD, Cardiac Department of the Voivodship Emergency Service and Medical Transport Station “Meditrans” (WSPRiTS “Meditrans”), ul. Poznańska 22, 00-685 Warszawa, Poland, e-mail: jerzy.rekosz@meditrans.waw.pl 


\section{Introduction}

Pre-hospital medical aid is administered by medical rescue teams to help people whose life has been threatened, or whose health has deteriorated in a significant way. The effectiveness of the medical operations undertaken in the pre-hospital phase has a significant impact on the effects of hospital treatment. The outcome of the therapy is a result of both pre-hospital first aid and hospital treatment.

The effectiveness of first aid depends on the knowledge and experience of medical rescue team members: physicians, nurses and paramedics. Due to the rapid development of diagnostic methods and the implementation of modern therapies, including various invasive treatment methods, and the implantation of life-saving devices, the work of the medical personnel operating in the pre-hospital phase is becoming more and more demanding.

On the one hand, medical progress encourages the development of knowledge and makes it possible to acquire the ability to interpret the results of the medical tests that have been performed, on the other hand, it should contribute to improving the diagnostic capacities at the disposal of medical rescue teams (MRTs).

The popularization of information and the implementation of such systems as e.g. 12-lead electrocardiogram (ECG) tele-transmission systems can provide enhanced support of this kind. The preliminary results of the analysis examining the functioning of tele-transmitting 12-lead standard ECG from the scene of the emergency incident to the Tele-transmission Center (TC) in Warsaw were presented in 2011 [1].

To evaluate the scale and structure of 12-lead ECG tele-transmissions and of the teleconsultation system which was implemented in the operations undertaken by basic MRTs. The study is based on observations made during the 4 years since the introduction of the method.

\section{Methods}

From September 2009 (the time when the standard ECG tele-transmission system was launched) to August 2013, basic medical rescue teams (BMRTs) of the Voivodship Emergency Service and the "Meditrans" Medical Transport Station (VES and MTS "Meditrans") in Warsaw implemented 12-lead ECG tests at the scene of the emergency incident (Fig. 1).

According to the procedure that was put in place, the trace obtained was transmitted to the TC located in the Cardiac Department of "Meditrans". Relying on the ECG test and the information about the patient, a TC physician, i.e. a cardiologist or a cardiology fellow with at least 3 years of training on 24/7 duty, advised the BMRT leader on the further procedure of managing the patient, including the selection of the target hospital. When acute coronary syndrome (ACS) was evident or highly probable, the consultant physician arranged for the patient to be admitted to 1 of the 11 Warsaw centers which performed primary percutaneous coronary intervention (PCI) and were on $24 / 7$ hemodynamic duty.

According to the procedure approved in the Warsaw "Meditrans" service, which is compliant with the ISO 9001:2009 Quality Management System, tele-transmission and teleconsultation time may not exceed $10 \mathrm{~min}$. If a BMRT did not receive feedback from the consultant physician within that time-limit, the patient was transported to the nearest hospital. What also deserves emphasis is the principle that the team is obliged to keep travelling with the patient during tele-transmission and teleconsultation. Such a procedure reduced the risk of extending the time of intervention and transport of the patient to the hospital.

Indications for performing standard ECG at the scene of the incident included: 1 . Chest pain, 2 . Dyspnea or 3 . Any other symptoms that might

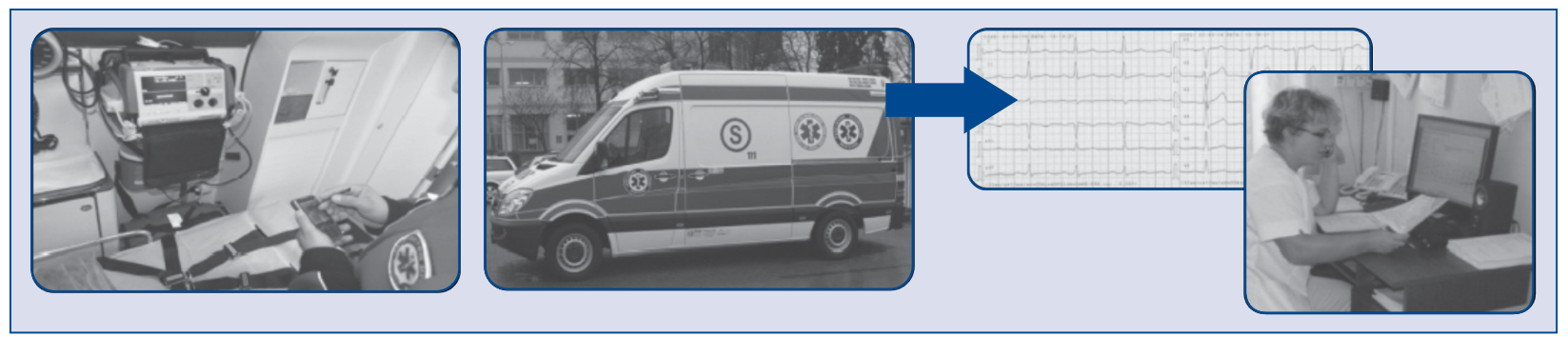

Figure 1. The 12-lead electrocardiogram tele-transmission system in Voivodship Emergency Services and Medical Transport Station "Meditrans" in Warsaw. 


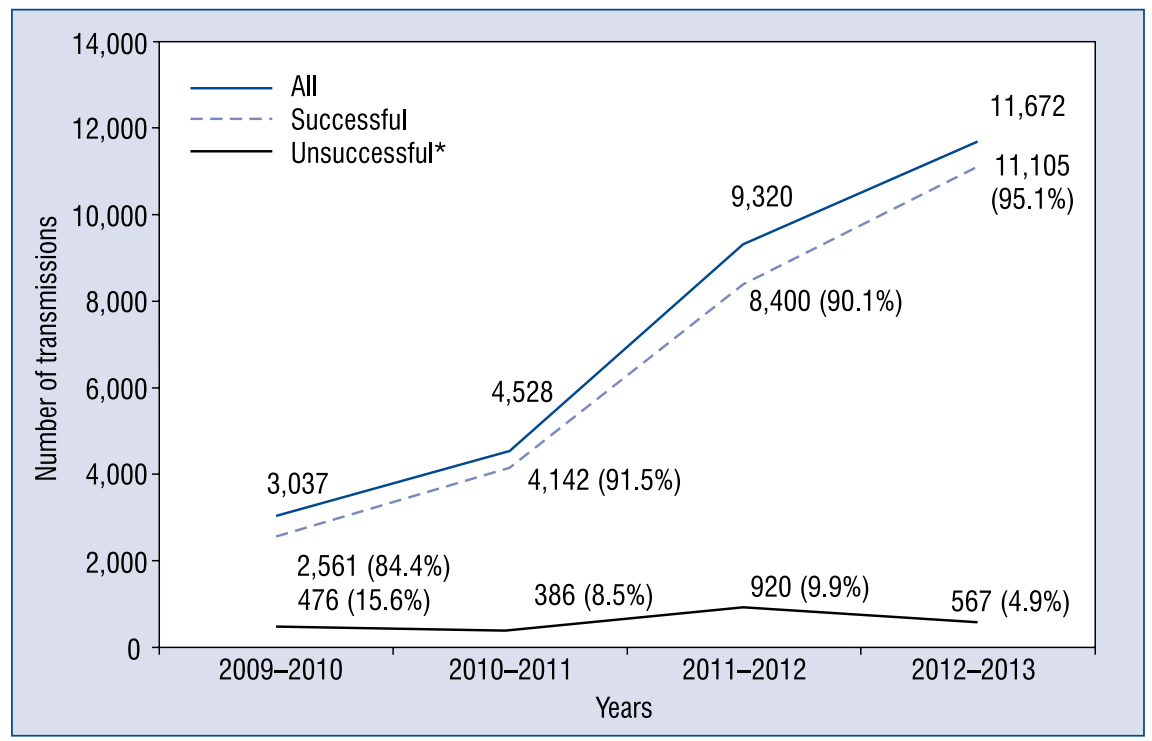

Figure 2. The 12-lead electrocardiogram (ECG) tele-transmissions made by basic medical rescue teams (BMRTs) over the 4-year period of the system operation ( $n=28,557$ ); *Unsuccessful ECG transmissions from BMRT to Teletransmission Center.

suggest an acute coronary syndrome, such as: 4. Dizziness or syncope, 5 . Cardiac arrhythmia, 6. Palpitations and 7 . Anything else that led the BMRT leader to make such a decision in unlisted situations. In the "Meditrans" operating region, medical rescue services were provided by 22 BMRTs in 2009 and 2010, 31 in 2011-2012 and 37 in 2013.

\section{Results}

The total number of interventions made by BMRTs from September 2009 to August 2013 was 383,347 . During the 4 -year period when the system was in operation, i.e. over the time-span analyzed in the present paper, the teams made 12-lead ECG transmissions in $28,557(7.4 \%)$ subjects. The teams recorded $26,208(91.8 \%)$ successful tele-transmissions, while $2,349(8.2 \%)$ tests failed to reach the TC for technical reasons (lead disconnection record failure, trembling records and transmission net transient loss).

The patients whose ECGs were transmitted were 62 years old on average. Women prevailed in the group examined, constituting $56 \%$ of the cases. The average time of data tele-transmission and consultation was 6 min $12 \mathrm{~s}$. The minimum and maximum time recorded was $3 \mathrm{~min} 20 \mathrm{~s}$, and 9 min 52 s, respectively.

A detailed analysis of the number of the teletransmissions performed indicated an absolute growth at the particular stages analyzed (the number of tele-transmissions over time is shown in Figure 2). The highest number of the ECG traces performed, i.e. 11,672 tests, was recorded in the period from 2012 to 2013. It was at least 3.5-fold compared to that in the first year of the system's operation, when 3,037 ECG transmissions were made.

An upward trend in the number of successful tele-transmissions in the years under analysis was observed. The relative number of unsuccessful ECG transmissions decreased, with the smallest percentage of $4.9 \%$ recorded in the latest part of 2012-2013. The number of all the interventions made by BMRTs in the periods analyzed was: in 2009-2010 - 108,277; in 2010-2011 - 111,324; in $2011-2012$ - 125,298 and in $2012-2013$ 138,448 .

The most common indication for using the ECG tele-transmission system was chest pain, accounting for 8,724 (30.5\%) cases. Twenty-seven point three percent of those tele-transmissions concerned patients with chest pain but without the ST-segment or T wave changes in ECG (Fig. 3). Lesions suggesting or evident of ACS, were found in $5.9 \%$ of the cases, $2.1 \%$ of which were ACS with the ST-segment elevation (STEMI) and 3.8\% without the ST-segment elevation (NSTEMI).

Cardiac arrhythmias were the second most common group of reasons for performing ECG, accounting for $20.5 \%$ of the cases, while the third one were either dizziness or syncope, which constituted $15.1 \%$ of the cases overall. 


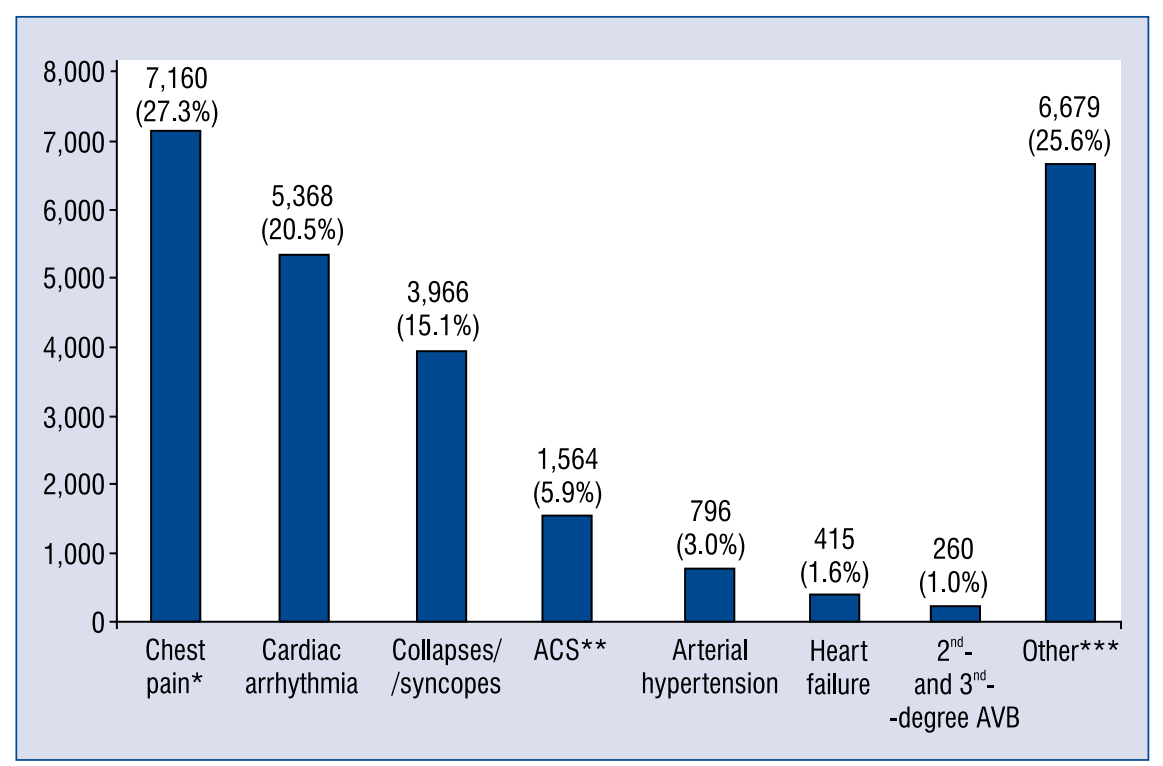

Figure 3. The cases of basic medical rescue teams (BMRTs) interventions where 26,208 electrocardiogram (ECG) transmissions were successful over 4 years of the system operation; *Without ST-segment or T wave changes in ECG; ${ }^{* *}$ Acute coronary syndrome (ACS) chest pain and ST-segment or T wave changes in ECG; ***In each situation when BMRT leader decides to perform and transmit ECG; AVB - atrioventricular block.

An analysis of the group with cardiac arrhythmias or palpitations (5,368 cases) proved that the most frequently diagnosed arrhythmia was atrial fibrillation (AF), with $82 \%$ of such cases being paroxysmal. In $17.3 \%$ of the cases, in spite of the patient reporting a disturbed heart rhythm, ECG did not reveal any arrhythmia at that moment (major groups of arrhythmic diagnoses are shown in Figure 4). Among the 1,489 ECGs that were transmitted with the "arrhythmia" code but were not $\mathrm{AF}$, the following problems were diagnosed: supraventricular and ventricular tachycardia, premature atrial and ventricular complexes, and sinus tachycardia (subgroup shown in Figure 5).

The ECG test was performed in up to $3.0 \%$ of the cases due to arterial hypertension, heart failure, and $2^{\text {nd }}$ - and $3^{\text {rd }}$-degree atrioventricular block (AVB). The usefulness of the system for initial diagnoses and for making appropriate decisions whether to transport patients to hospital or not, were also evaluated. While all the patients with STEMI were directly referred to cardiac centers with PCI available on duty, in other ACS cases and in conditions of a different kind, the system allowed selection and transport to various hospitals (the types of hospitals with cardiology centers where patients were transferred on the basis of the teletransmission diagnosis is shown in Figure 6).

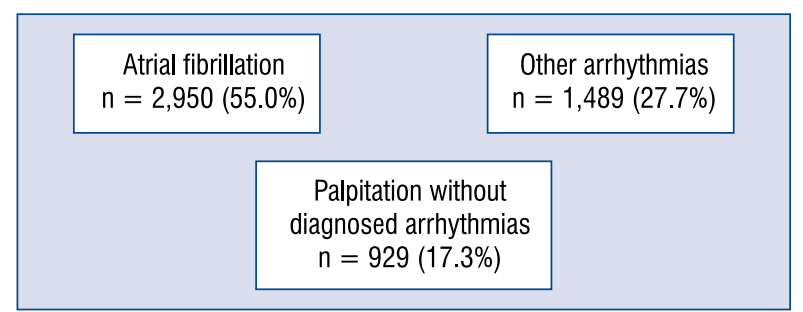

Figure 4. Electrocardiogram (ECG) tele-transmissions ( $n=5,368$ ) made in the event of calls to the reported feeling of disturbed heart rhythm.

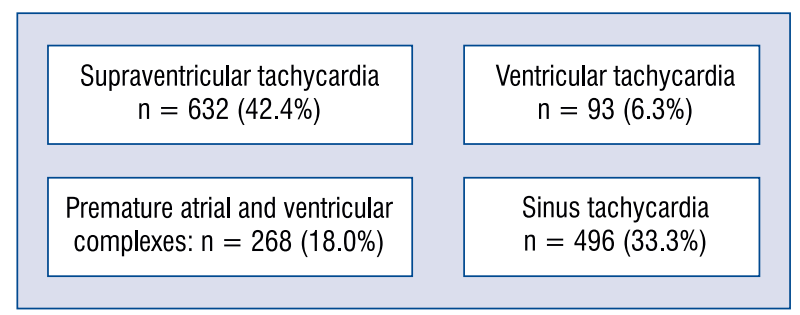

Figure 5. Other arrhythmias $(n=1,489)$ recorded by electrocardiogram.

\section{Discussion}

The Act on National Medical Rescue of 8 September 2006 changed the organization and 


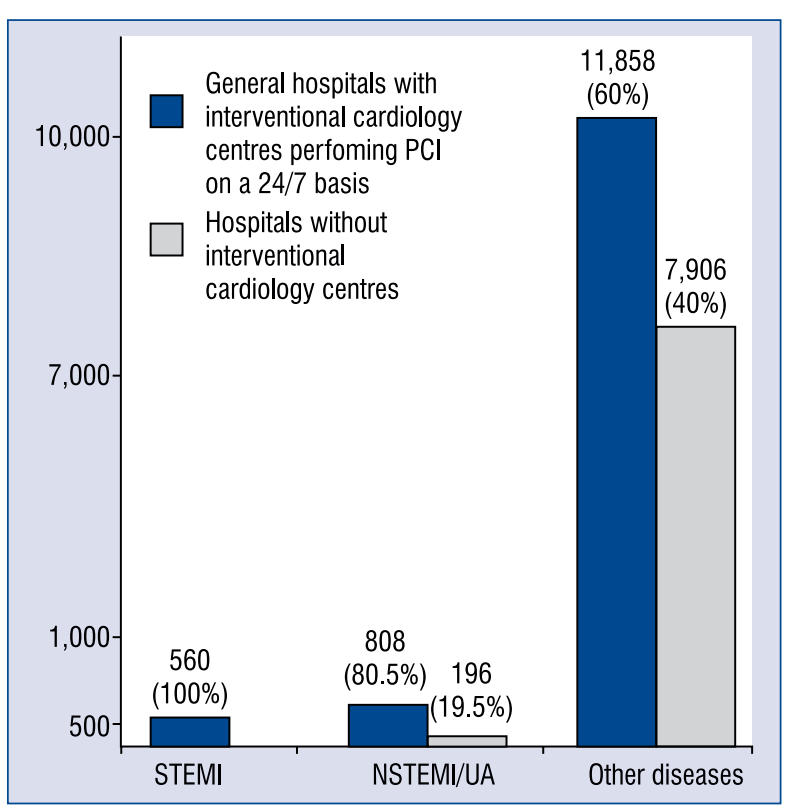

Figure 6. Transport of patients to hospitals after teletransmission and teleconsultation; STEMI — ST elevation myocardial infarction; NSTEMI - non-ST elevation myocardial infarction; UA - unstable angina; $\mathrm{PCl}$ - percutaneous coronary intervention.

functioning of pre-hospital aid administered by medical rescue services [2]. Establishing only two types of medical rescue teams: specialist and basic, was one of the most significant changes implemented. A physician and a nurse and/or a paramedic are members of a specialist ambulance. The basic team operates without a physician.

The increasing number of medical services provided by teams without a physician became an impulse for the management of "Meditrans" in Warsaw to develop a system which would substantially support nurses and paramedics who are BMRT members. Approximately 1 million people in Poland are hospitalized due to cardiovascular diseases and even more patients report symptoms of a cardiovascular episode to medical dispatch centers. This is one of the reasons why the standard ECG tele-transmission and teleconsultation system was launched. Furthermore, Emergency Medical Service staff may have difficulties in ECG interpretation [3]. There is measurable proof that ECG transmissions from the scene of the emergency incident to interventional cardiology laboratories performing PCI in ACS are beneficial [4-6]. However, previously there had been no systemic solutions and until 2009 most patients with a suspicion of a cardiovascular episode were transported to the nearest hospitals.
It must be emphasized that neither earlier reports by members of both types of teams nor current studies regarding ECG transmission time as conducted by BMRTs have proven that the time of their operations was extended [7]. The ECG performance and transmission times that have been recorded did not exceed $10 \mathrm{~min}$ in the entire group examined and hence were compliant with the guidelines of the European Society of Cardiology (ESC) [8]. Thus, it can be concluded that the system improved the BMRTs' capacities for early diagnostics without extending the pre-hospital intervention time.

The continuously growing number of teletransmissions performed in the particular periods analyzed proved the system being increasingly accepted and that nurses and paramedics found it useful and helpful in their everyday operations. Moreover, it can be assumed that the system was used reasonably and in accordance with the principles adopted, since tele-transmission was used in $7.5 \%$ of all the BMRT interventions over the entire period analyzed.

The most frequent reason for performing a standard ECG test was chest pain. Cases where no electrographic evidence of ischemia was found were prevalent in that group. The tele-transmission system permitted better identification of patients with an acute coronary episode among those with chest pain. Owing to that, BMRT members supported by the consultant physician were able to make a good choice of the cardiac center or hospital to which the patients with the above symptoms should be transported.

Such a procedure seems to have contributed to reducing the overburdening of invasive cardiology laboratories with cases in which it was possible to perform initial diagnostics and treatment in other centers. It must be emphasized that hospitals which have hemodynamic laboratories are general centers which perform not only PCI. Therefore, in the past, patients with ACS who did not require coronary angioplasty and those with other cardiovascular and internal diseases were also transported to such hospitals.

Although the group of patients with ACS was not large in the material analyzed, it is justified to claim that BMRT operations have complied with the guidelines of the ESC pointing to $\mathrm{PCI}$ as the basic coronary artery revascularization method in ACS [8]. Therefore, all the STEMI cases were transported by BMRTs to intervention cardiology centers. In the case of such patients, the treatment that was applied after obtaining the agreement 
of a TC consultant physician consisted in the administration of acetylsalicylic acid and clopidogrel per os and using unfractionated heparin boluses intravenously. Such a procedure enhanced the effectiveness of the interventional therapy.

Team operations using the tele-transmission system ensured that the procedure complied with ESC guidelines also in NSTEMI cases [9]. This was confirmed by their making correct decisions regarding triage and the transport of patients to various centers, also those without hemodynamic laboratories, since not every NSTEMI case requires PCI within the initial $24 \mathrm{~h}$. Such decisions should involve not only medical but also economic and organizational aspects. Domestic and foreign reports prove there is a growing number of NSTEMI cases in comparison to STEMI ones [10, 11]. Therefore, in this phase it seems reasonable to use an ECG tele-transmission system which enables pre-hospital ACS differentiation and identifies those cases which require immediate PCI. Nevertheless, further in-hospital risk stratification in the NSTEMI population suggests that the conclusions coming from pre-hospital ECG transmission should be made very cautiously [9]. Polish original data on ACS patients referred to invasive cardiology lab hospitals using the ECG tele-transmission and tele-consultation system has shown a significant reduction of the delay in implementing effective treatment. An upward trend is shown in almost 10-year experience of the members participating in the system [12].

The second largest group of patients in the material under discussion were those with cardiac arrhythmias, among whom $\mathrm{AF}$ were the most numerous cases. Atrial fibrillation is the most common form of arrhythmia, particularly in the population of patients over 70 years old. Frequent arrhythmias, particularly their paroxysmal form, with subsequent episodes, should be handled with due care. It must be emphasized that an attack of $\mathrm{AF}$ involves the risk of ischemic stroke, heart failure, and in some cases increases mortality [13-16].

Sometimes, in unconfirmed arrhythmia episodes, the correct diagnosis is not at first given, especially when the arrhythmia becomes intermittent. Such cases, the frequency of which can reach nearly $20 \%$, pose a threat to the patient's life, as it can take more time until aid is administered, which means the increase of the probability that the complications mentioned above will occur [17]. On the other hand, heart palpitations may sometimes be a very subjective feeling and it is known that such cases - especially in emotionally sensitive patients - are a significant burden on medical teams. In such unclear cases, diagnosis should therefore benefit from the fact that BMRTs are able to perform single or multiple standard ECG tests.

While the majority of the patients with an attack of AF should be transported to the hospital emergency department or the casualty department, in many cases of persistent or chronic mildly or asymptomatic $\mathrm{AF}$, transport to hospital is unnecessary. Early diagnosis and a history of managed chronic arrhythmia allows the patient to stay at home and further treatment can be agreed on with the General Practitioner. At the same time, it is possible to relieve hospitals and prevent them from being overburdened with chronic cases.

Although patients with a disclosed $2^{\text {nd }}$ - and $3^{\text {rd }}$ -degree AVB were a small group among the cases presented, they deserve to be mentioned, because such conditions are life-threatening. The acquired AVB with an etiology other than coronary artery disease is normally idiopathic and affects elderly people. Apart from structural heart lesions, additional factors facilitating abnormal automaticity and conduction disorders in the heart among the population of people over 65 years old include: antiarrhythmic agents applied due to arrhythmia and/or heart failure, concomitant renal failure, and electrolyte imbalance $[18,19]$. The population of elderly people is increasing and so is the number of calls to incidents of collapse, syncope, which might be caused by sick sinus syndrome or AVB. BMRTs have electrotherapy equipment at their disposal and in the case of serious arrhythmias can perform electrical defibrillation or cardioversion but they cannot use the external stimulation option on their own. This is stipulated by relevant regulations. The tele-transmission and teleconsultation system can be used to modify the above principles. A TC consultant gives a diagnosis and decides whether there are grounds for external stimulation of the patient's heart, and BMRT members could implement the life-saving procedure under the consultant's supervision. Systematic introduction of tele-consultation solutions may also lead to reducing health-care costs, as demonstrated by the extensive data regarding pre-hospital telemedicine of ECG triage in more than 100 thousand acute cardiac disorder patients [20].

\section{Medical perspectives}

In Warsaw and the Warsaw region, "Meditrans" medical rescue teams usually react to $500-600$ calls a day, $65 \%$ of which are served by BMRTs. It seems that in accordance with European standards, also in 
Poland even more pre-hospital phase interventions will be made by paramedics and system nurses. It is BMRT members that will more and more often give the initial diagnosis, perform triage, and provide information to the physician on duty in the target hospital. Hence, it seems reasonable to secure and support their operations. At the same time, training nurses and paramedics in ECG interpretation should be continued and expanding their medical knowledge, particularly regarding modern diagnostic and therapeutic methods, should be carried on. The acquired knowledge and skills, supported by immediate feedback from the tele-transmission system, might make it possible to extend the scope of therapeutic qualifications for nurses and paramedics when providing medical rescue services.

\section{Limitations of the study}

The article presents the analysis of the increasing scale and structure of tele-transmission over the 4-year period under discussion in one of the Polish provinces. The vast population of patients taken to the numerous hospitals in this area means that exploring all the source hospital data and defining outcomes was beyond the possibility of the authors. Thus, neither interesting results concerning final verification of the diagnosis, nor comparison with the pathway where the work done by BMRTs was performed without the possibility of tele-transmission can be shown. Moreover, it cannot be ruled out that delays in patient care due to tele-transmission did occur.

\section{Conclusions}

1. The introduction of the tele-transmission and teleconsultation system constitutes a more and more frequently used method to support BMRTs in their everyday operations and is widely implemented to diagnose vast populations of patients.

2. 12-lead ECG transmission and consultations with a physician were helpful in extending the diagnostic capacities of rescue teams and exerted a beneficial impact on cardiovascular patient triage and the selection of the target hospital.

3. It seems reasonable to introduce 12-lead ECG tele-transmission as a standard procedure in all the basic Emergency Medical Service teams.

Conflict of interest: None declared

\section{References}

1. Rekosz J. Teletransmisja w systemie pogotowia ratunkowego. In: Piotrowicz R, Rużyło W eds. Telekardiologia. Część I. Wybrane zastosowania kliniczne, Instytut Kardiologii im. Prymasa Tysiąclecia Stefana Kardynała Wyszyńskiego, Warsaw, 2011.

2. Act on National Medical Rescue of 8 September 2006, Dz.U. (Journal of Laws of the Republic of Poland), No. 191, item 1410.

3. Koźluk E, Timler D, Zyśko D et al. Members of the emergency medical team may have difficulty diagnosing rapid atrial fibrillation in Wolff-Parkinson-White syndrome. Cardiol J, 2015; 22: 247-252. doi: 10.5603/CJ.a2014.0086.

4. Dudek D, Legutko J, Siudak $Z$ et al. Invasive treatment strategies in patients with myocardial infarction in Poland. Kardiol Pol, 2010; 68: 618-824.

5. Karcz M, Bekta P, Skwarek M et al. Rozpowszechnienie teletransmisji EKG w przedszpitalnym postępowaniu z chorymi z podejrzeniem ostrego zawału serca: Efekty programu pilotażowego POLKARD na Mazowszu. Post Kardiol Interw, 2006; 2: 274-280.

6. van't Hof AWJ, van de Wetering $\mathrm{H}$, Ernst $\mathrm{N}$ et al. On behalf of the On-TIME study group. A quantitative analysis of the benefits of pre-hospital infarct angioplasty triage on out-come in patients undergoing primary angioplasty for acute myocardial infarction. Eur Heart J, 2005; 7 (suppl. K): K36-K40.

7. Rekosz J, Gałązkowski R. 12-lead ECG tele-transmission in emergency medicine teams' actions. Wiad Lek, 2013; 66: 219-225.

8. Steg PG, James SK, Atar D et al. ESC Guidelines for the management of acute myocardial Infarction in patients presenting with ST-segment elevation: The Task Force on the management of ST-segment elevation acute myocardial infarction of the European Society of Cardiology (ESC). Eur Heart J, 2012; 33: 2569-2619.

9. Authors/Task Force members. Windecker S, Kolh P, Alfonso F et al. ESC/EACTS Guidelines on myocardial revascularization: The Task Force on Myocardial Revascularization of the European Society of Cardiology (ESC) and the European Association for Cardio-Thoracic Surgery (EACTS)Developed with the special contribution of the European Association of Percutaneous Cardiovascular Interventions (EAPCI). Eur Heart J, 2014; 35: 2541-619. doi: 10.1093/eurheartj/ehu278.

10. Poloński L, Gąsior M, Gierlotka M et al. What has changed in the treatment of ST-segment elevation myocardial infarction in Poland 2003-2009? Data from the Polish Registry of Acute Coronary Syndromes (PL-ACS). Kardiol Pol, 2011; 69: 1109-1118.

11. Yeh RW, Sidney S, Chandra M et al. Population trends in the incidence and outcomes of acute myocardial infarction. N Engl J Med, 2010; 362: 2155-2165.

12. Kleinrok A, Płaczkiewicz DT, Puźniak M et al. Electrocardiogram teletransmission and teleconsultation: essential elements of the organisation of medical care for patients with ST segment elevation myocardial infarction: A single centre experience. Kardiol Pol, 2014; 72: 345-354. doi: 10.5603/KP.a2013.0352.

13. Healey JS, Connolly SJ, Gold MR et.al.; for the ASSERT Investigators. Subclinical atrial fibrillation and risk of stroke. N Engl J Med, 2012; 366: 120-129.

14. Wang TJ, Larson MG, Levy D et al. Temporal relation of atrial fibrillation and congestive heart failure and their joint influence on mortality. The Framingham Heart Study. Circulation, 2003; 107: 2920-2925. 
Cardiology Journal 2015, Vol. 22, No. 6

15. Soliman EZ, Safford MM, Muntner P et. al. Atrial fibrillation and the risk of myocardial infarction. JAMA Intern Med, 2014; 174: 107.

16. Chen LY, Sotoodehnia N, Bužková P et. al. Atrial fibrillation and the risk of Sudden Cardiac Death. The Atherosclerosis Risk in Communities Study and Cardiovascular Health Study. JAMA Intern Med, 2013; 173: 29-35.

17. Flaker G, Belew K, Beckaman K et al. Asymptomatic atrial fibrillation. Demographic features and prognostic information from the Atrial Fibrillation Follow-up Investigation of Rhythm management (AFFIRM) study. Am Heart J, 2005; 149: 657-663.
18. Mangrum JM, DiMarco JP. The evaluation and management of bradycardia. N Engl J Med, 2000; 342: 703-709.

19. Kowalik R, Rekosz J. Jatrogenne hiperkaliemia u osób starszych. Stany zagrożenia życia. Miejsce sztucznej stymulacji serca. Opis 3 przypadków. Kardiol. Pol, 2003; 59: 47-53.

20. Brunetti ND, Dellegrottaglie G, Lopriore C et al. Prehospital telemedicine electrocardiogram triage for a regional public emergency medical service: is it worth it? A preliminary cost analysis. Clin Cardiol, 2014; 37: 140-145. doi: 10.1002/clc. 22234 . 